\title{
FX JOB RECRUITMENT
}

\author{
Padmanaban $^{1}$ and Sujitha ${ }^{2}$ Muppidathi@ Priya ${ }^{3}$ \\ ${ }^{1}$ Department of Computer Application, Francis Xavier Engineering College \\ ${ }^{2}$ AP,Department of Computer Application, Francis Xavier Engineering \\ College
}

${ }^{2}$ Department of Computer Application, Francis Xavier Engineering College

\begin{abstract}
In this project present a secure and privacy-preserving access control to users, which guarantee any member in a group to anonymously utilize the cloud resource. Moreover, the real identities of data owners can be revealed by the group manager when disputes occur. In this project provide rigorous security analysis, and perform extensive simulations to demonstrate the efficiency of our scheme in terms of storage and computation overhead. Cloud computing provides an economical and efficient solution for sharing group resource among cloud users. Unfortunately, sharing data in a multi-job portal manner while preserving data and identity privacy from an un trusted cloud is still a challenging issue, due to the frequent change of the membership .
\end{abstract}

The major aims of this method a secure multi-owner data sharing scheme. It implies that any user in the group can securely share data with others by the un trusted cloud. This scheme is able to support dynamic groups. Efficiently, specifically, new granted users can directly decrypt data files uploaded before their participation without contacting with data owners. User revocation can be easily achieved through a novel revocation list without updating the secret Keys of the remaining users. The size and computation overhead of encryption are constant and Independent with the number of revoked users.

Job portal is developed for creating an interactive job vacancy for candidates. This web application is to be conceived in its current form as a dynamic site-requiring constant updates both from the seekers as well as the companies. On the whole the objective of the project is to enable jobseekers to place their resumes and companies to publish their vacancies.

\section{KEYWORDS}

Network Protocols, Wireless Network, Mobile Network, Virus, Worms \&Trojon

\section{INTRODUCTION}

Traditional education is defined as teacher-centered delivery of instruction to classes of students who are the receivers of information. Traditional institutions generally stress basic educational practices and expect mastery of academic learning in the core subjects. Most organizations generally follow this educational model[8]. On the other hand, an online educational or e-learning service is a website, which teaches and helps students improve in certain subjects[5]. These are normally, used by institutes to let students learn from home and complete online homework. 
Traditional education is not necessarily the most effective way of learning, because no student can pay full of attention to the class lectures, and it cannot be possible for a student to attend the class regularly. So due to many reasons such as lack of concentration, absent to the class, wrong understanding of the concept, etc., the education system may face a poor outcome. Another factor is that, a lecturer may not handle an efficient teaching methodology. E-learning as a method of education makes the learners undergo contemplation, remoteness, as well as lack of interaction or relation. It therefore requires a very strong inspiration as well as skills with to the management of time in order to reduce such effects. With respect to clarifications, offer of explanations, as well as interpretations, the e-learning method might be less effective that the traditional method of learning. The learning process is much easier with the use of the face to face encounter with the instructors or teachers[2].

Both traditional and e-learning system has its own advantages and disadvantages. In order to overcome the disadvantages, the project propose an idea of converting the education system into active learning education, by sharing the videos of class lectures through online. This method will deliver the benefits of both traditional and e-learning system and makes the education more efficient.

\section{- Emily BAGARUKAYO, Ezra MWESIGWA(2017),}

This paper proposes and highlights the need of an online job board system for colleges and its effectiveness in bridging the gap between college students and career opportunities. Traditionally, employment websites have been used in HR management for finding candidates and in recruitment. This work is based on a job portal built for one of the leading engineering campuses of Nepal, Pulchowk Campus, which is a variation of such job boards designed specifically to serve the students of the Campus. With services like job recommendations to students based on their skills, and candidate filtering to assist companies in candidate matching, the system is expected to be of use for both students for exploring jobs, and companies to find potential candidates suited for the job.

\section{- Vijay Yadav(2019),}

This paper presents a designing of a web based system for Career Guidance and Employment Management System (CGEMS). Basically, CGEMS is tries to help a user who is looking for career advice guidance, or looking for their opportune job.

CGEMS tries to make one place where student, job seeker, career advisor or consultant, and various company or organization can meet and help. In order to help the users to determine their best career choice, this system also offers some tests or quizzes that are related to such career and the user personality which will be useful for the career path. Furthermore, users of CGEMS such as company or organization can post a job description, when they look for employee.

\section{- Vivek Kumar Sehgal (2013),}

In the current scenario, there is a rat race in each and every professional field. It is also true for job market. A job portal is a website dedicated for online information about recruiters as well as job seekers. A job portal helps both the job seekers and recruiters finding the right organization for the employees. In the case of job seekers, according to their educational qualification, experience and their preferences, the job portal shows the list of companies to the job seeker. And, to the recruiters, provides the suitable candidates from a pool of lacks. The objective of this application is to develop a system to enable interaction between employers and applicants. The 
determination is to allow communication between the interested parties and complete the task of recruitment quickly.

\section{- Marjan Mansourvar and Norizan Binti Mohd Yasin (2014),}

"Dreams Job" is an online Job Search Portal, a web application through which job seekers can register and apply for jobs. Through this portal employers can also post their jobs and review applications. The traditional recruitment systems are time taking and costly. A job seeker must find jobs through advertisements, college fairs, job fairs etc., and the employers must put in much effort to find the right candidate for a vacant position. This application addresses such shortcomings and is a convenient platform for both job seekers to find and apply for jobs and for employers to post jobs and review applications with much ease. Candidates can search for jobs in any field through advanced search capabilities. They can upload their resumes to this application which is stored for future use also. Employers can download these resumes and post/delete job positions. The admin controls this portal and makes the decision about companies and jobs that can access/appear in this portal. Candidates and Employers can use this portal without any geographical barrier, from any part of the world. This application is also developed by using some cutting-edge technologies that are in great demand in the IT industry today. Some of them are NodeJS, AngularJS, Sequelize ORM, etc.

\section{- Keethana Kopuri, Gulam Mujtaba Hussain Aqueel (2017),}

A job portal helps both the job seekers and recruiters finding the right organization for the employees. In the case of job seekers, according to their educational qualification, experience and their preferences, the job portal shows the list of companies to the job seeker. And, to the recruiters, provides the suitable candidates from a pool of lacks.

The objective of this application is to develop a system to enable interaction between employers and applicants. The determination is to allow communication between the interested parties and complete the task of recruitment quickly.

\section{- PAVAN P APARANJI, JAI PRAKASH TRIPATHI (2018),}

As cross-sectoral categories such as green jobs, ethical jobs and seasonal work. Users can usually submit their resumes and send them to potential employers and recruiters for review, while employers and recruiters can post job postings and search for potential employees. Niche job directories begin to play a bigger role in providing jobs and employees with more goals for the candidate or employer. Employment Councils, such as For example, airport jobs and federal jobs provide a very specific way to eliminate and reduce the time for the most appropriate

\section{Problem Statement}

\section{- Architecture Diagram}

Naukri.com", "Shine.com", etc. brought the revolution of transforming traditional way of job search into technological advancement called "Online job Portal". Initially, less number of trusted clients and improvement through advertisements and branding. Job recruitment links are provided only through Whatsapp group. Candidate have to upload resume for each drive. Any training given by company which was followed through circular mode. 


\section{- Job Analysis}

Traditional Job Analysis as a means to find a framework for many human resource practices. Traditional Job analysis is a time consuming process that is often focused more on the past and less on the behaviours we want to encourage today in employees.

\section{- $\quad$ - Job Portal}

It is a platform that joins recruiters and the job seekers to complete their goals and requirements. Recruiters look for a right candidate who has the right qualification to handle the responsibilities efficiently.

Simple and professional GUI for users of all qualification groups. Increased filtering for employees seeking job as a Fresher Or as an. Experienced individual. All the recruitment intimation provided in the website. Student can register all the recruitment drive using this website. Candidate also upload cv, which is use for further drive. Recruitment results also published. Student can register for training.

To improve the efficiency of verifying multiple tasks, we further extend our mechanism to support batch student. There are two interesting problems we will continue to study for our future work. One of them is traceability, which means the ability for the group manager to reveal the identity of the signer based on verification metadata in some special situations.

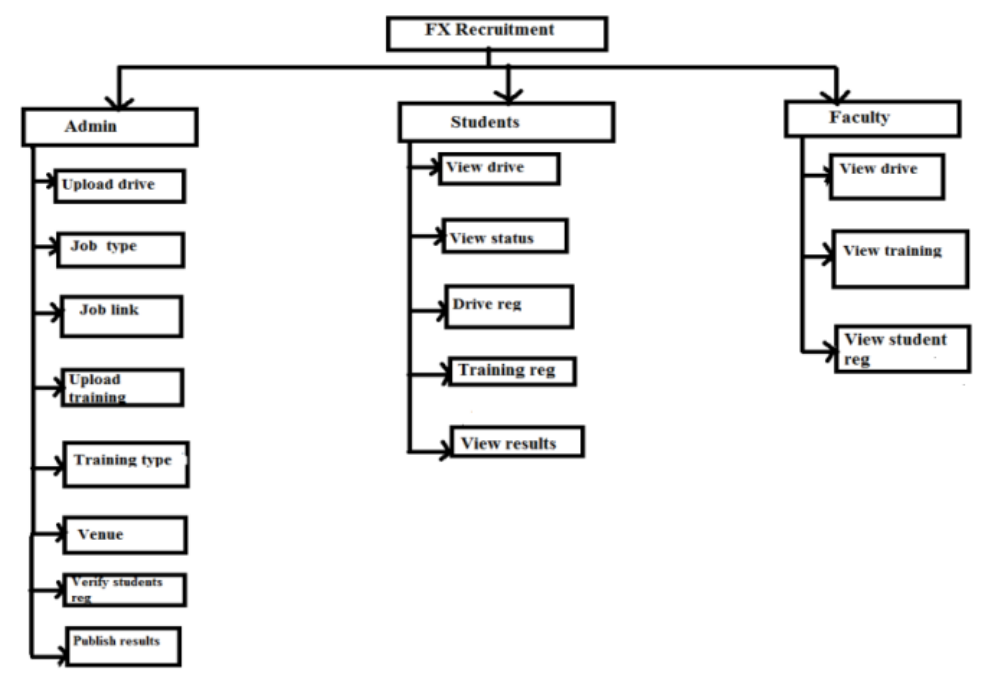

Figure:1

\section{EXPERIMENTS AND RESULTS}

\section{- Modules}

The The project "FX Job Recruitment" consists 5 modules for optimizing education system.
1) User and Admin Accounts
2) Mentor
3) Students 


\section{- USER AND ADMIN ACCOUNTS}

This module was build to manage the user registration, user authentication, Admin interface, user login and successful logout from the application. The user details are enrolled into the database with a registration form. Login form interfaces with the user to get the username and password, and authenticates the valid user. Admin accounts are managed with the MySQL Admin Interface. After logout of the user, the web application redirects to the Home page.

\section{- Mentor}

This module was created for the Mentor to give information about the Job Recruitment. The Mentor, will upload the drive and training details into the database, which can be accessed by the authenticated users. The Mentor can view the students details who are all apply for the drive as well as training. The Mentor can download the students cv through this Mentor know who are the candidates are apply for the drive. The Mentor can revocation the students from the group. After the completion, of the drive and training, Mentor can delete the details of the file.

\section{- Student}

This module allows the student apply for the drive and training. The students can access the drive and training details. The students can View which are all the drive are held today. The students can register for the drive by uploading the cv. The students can View all the OFFCampus drive.

\section{Output Screen}

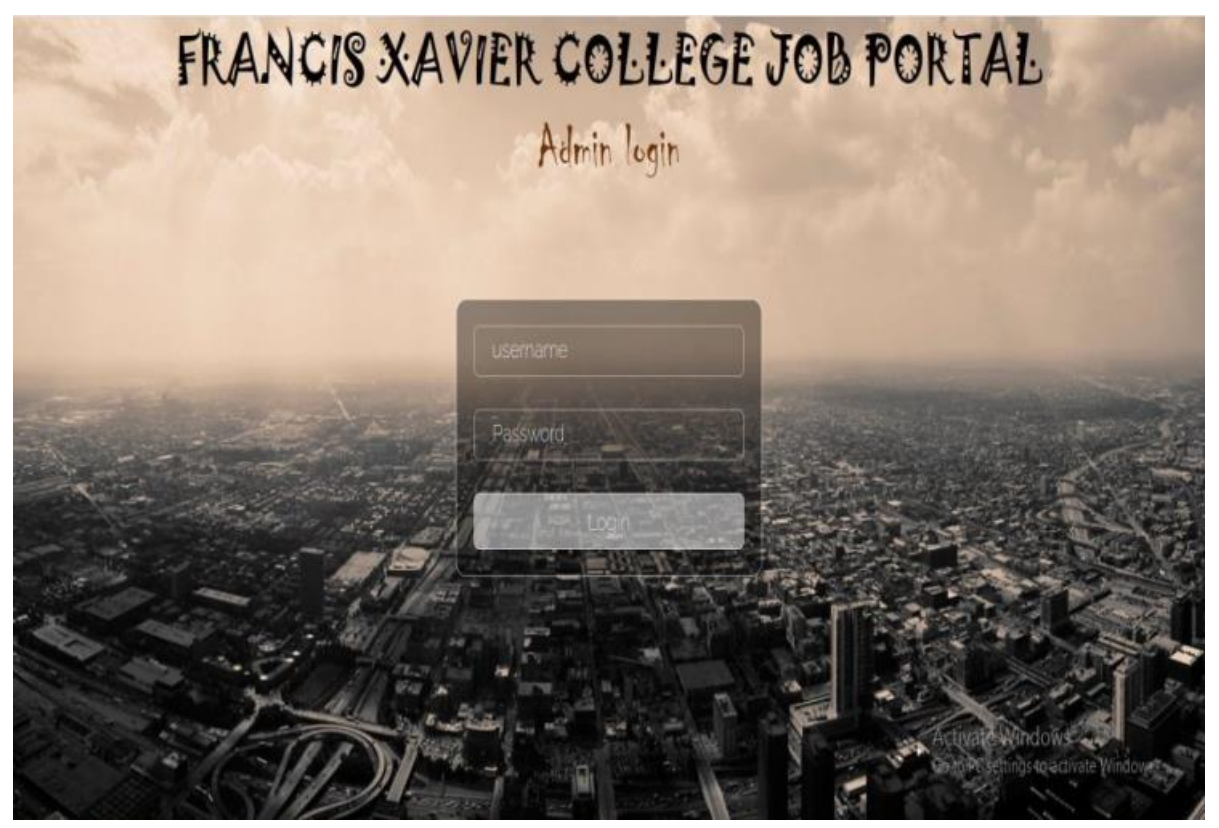

Figure: 2 Admin Login 


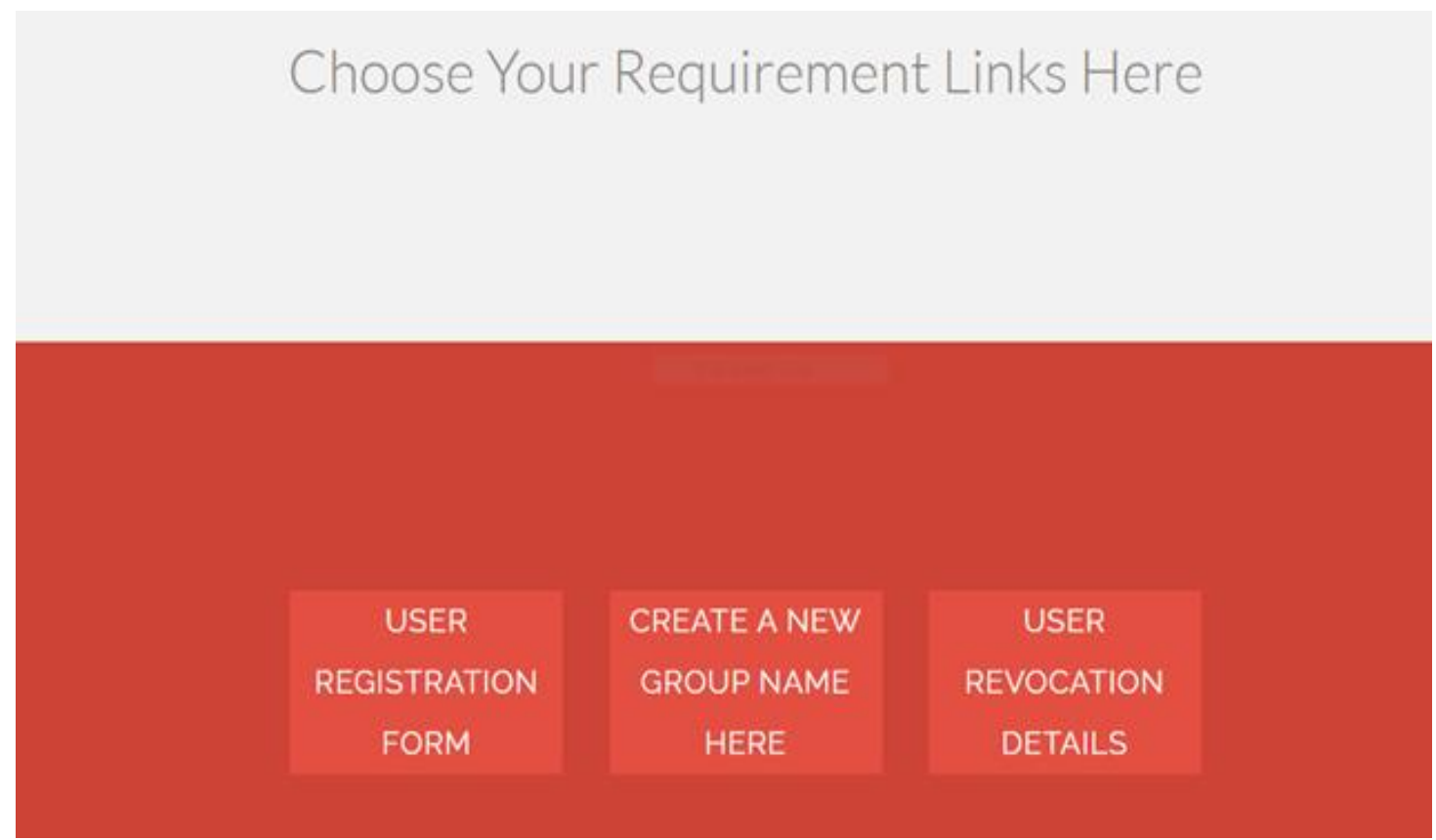

Figure: 3 Administrator Access

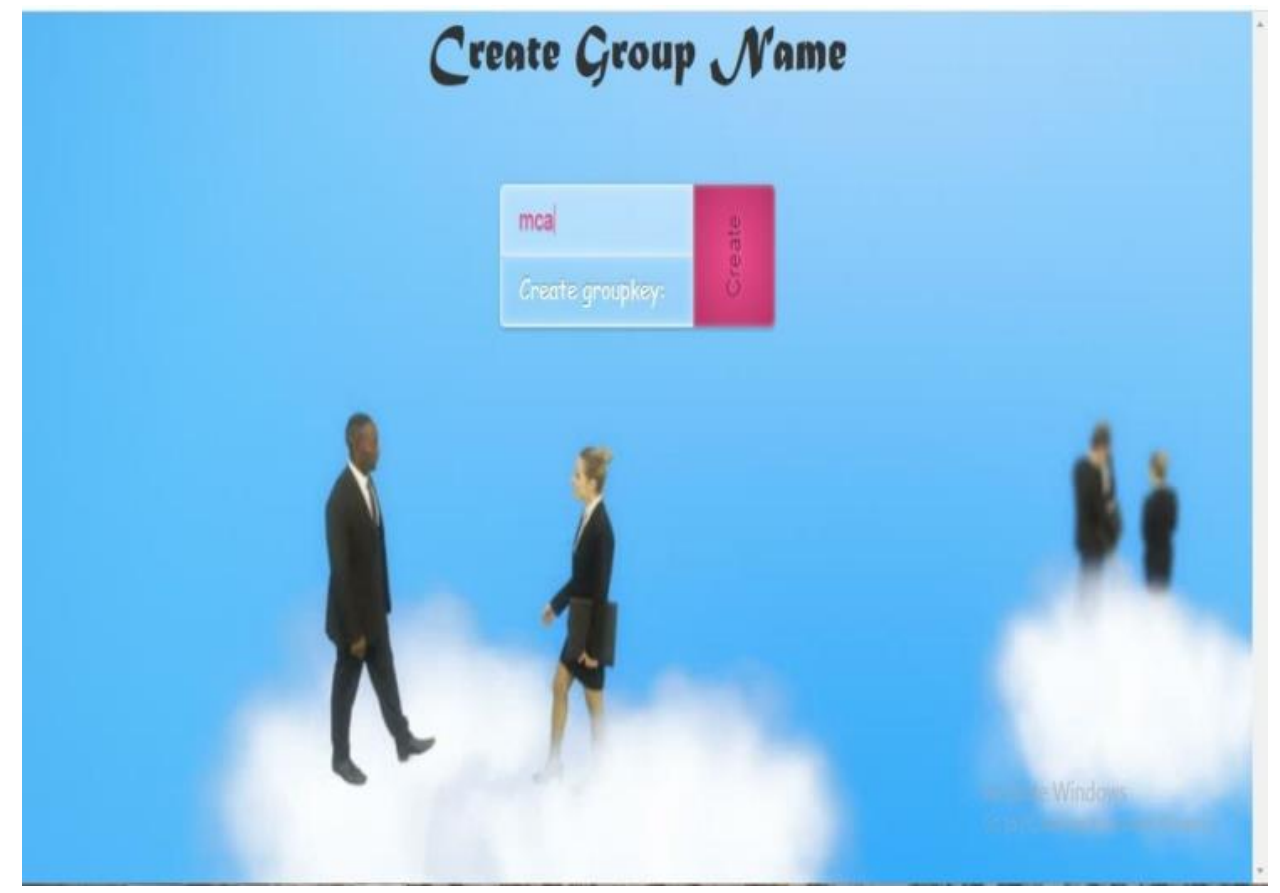

Figure : 4 Group Creation 


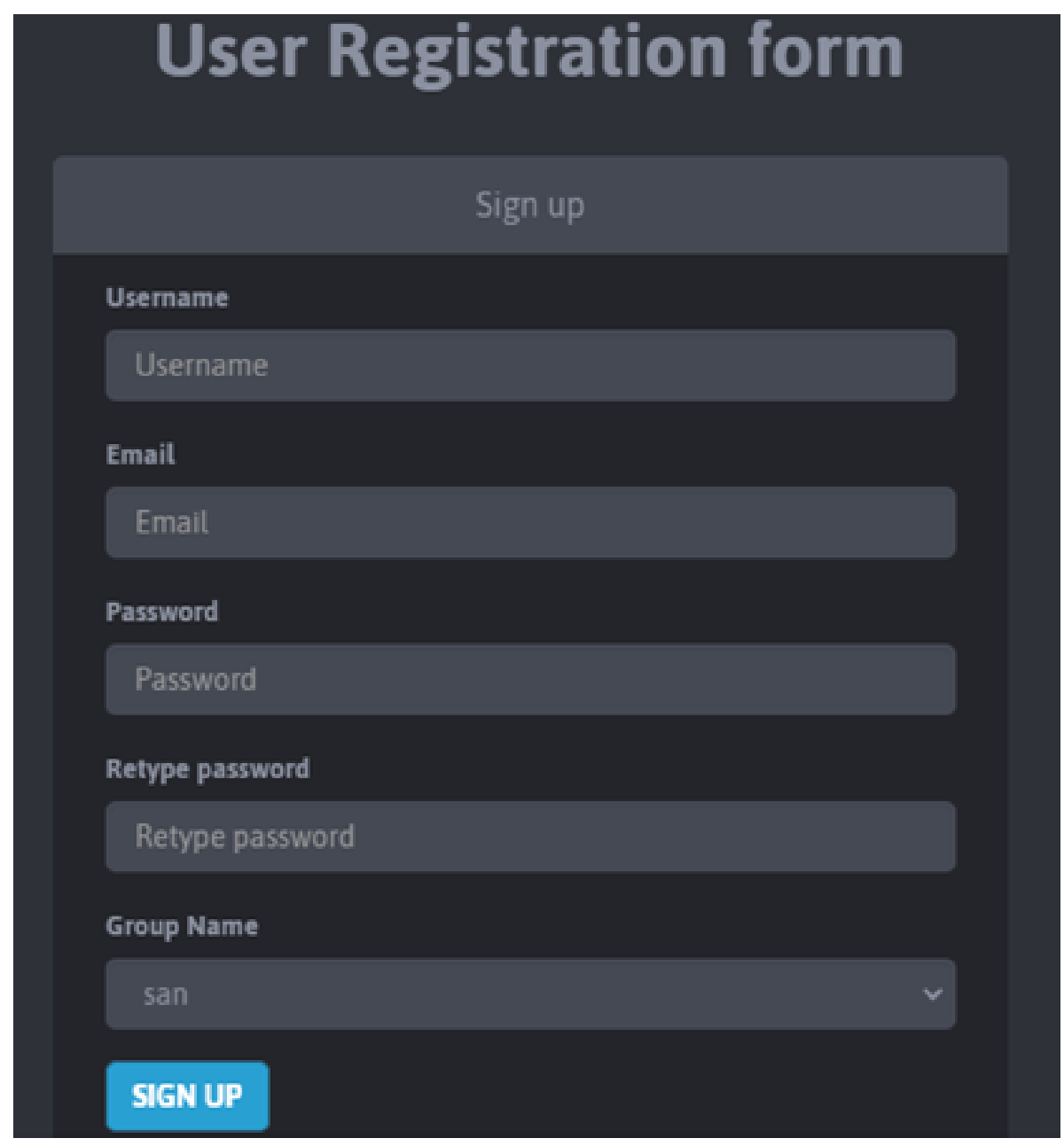

Figure : 5 Registration Form 


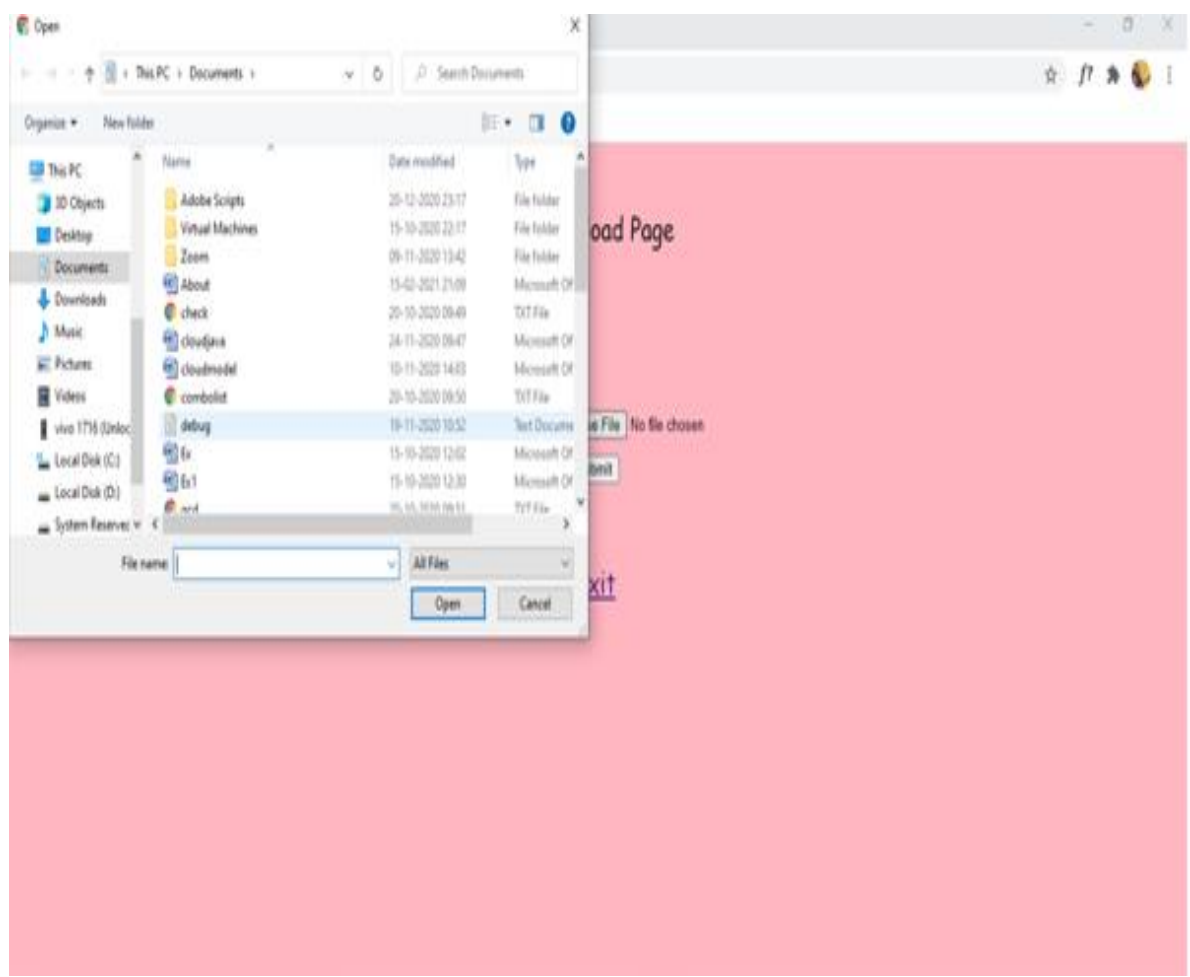

Figure: 6 Choose File

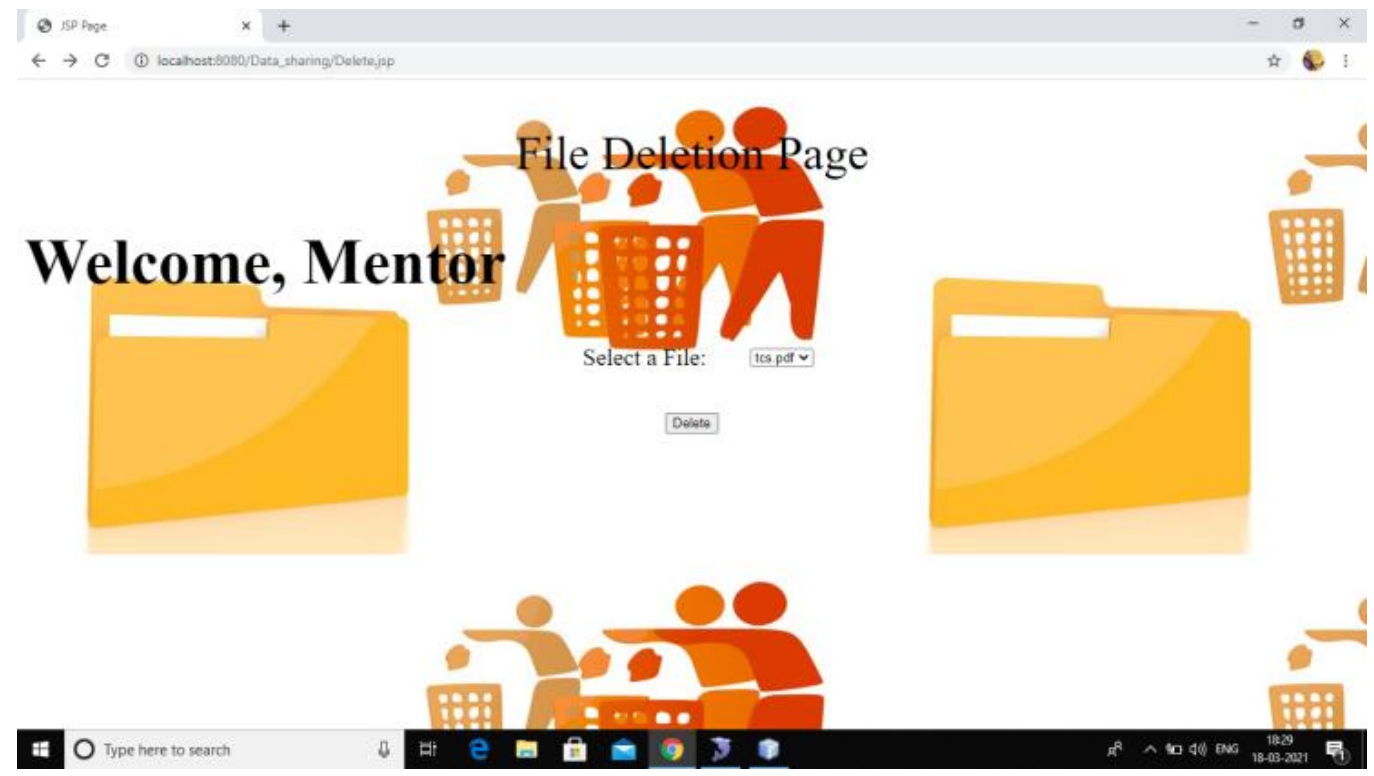

Figure :7 Deletion Page 

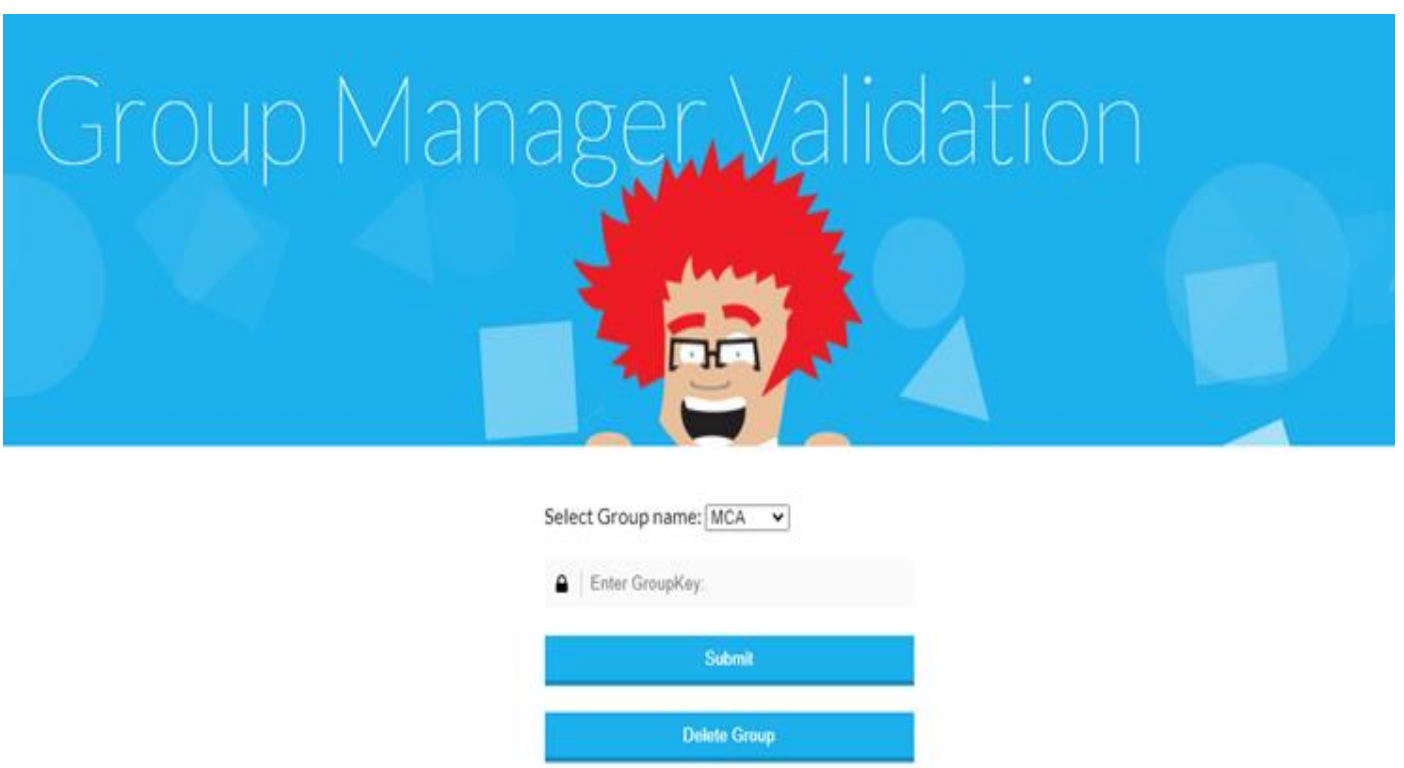

Figure: 8 Group Validation

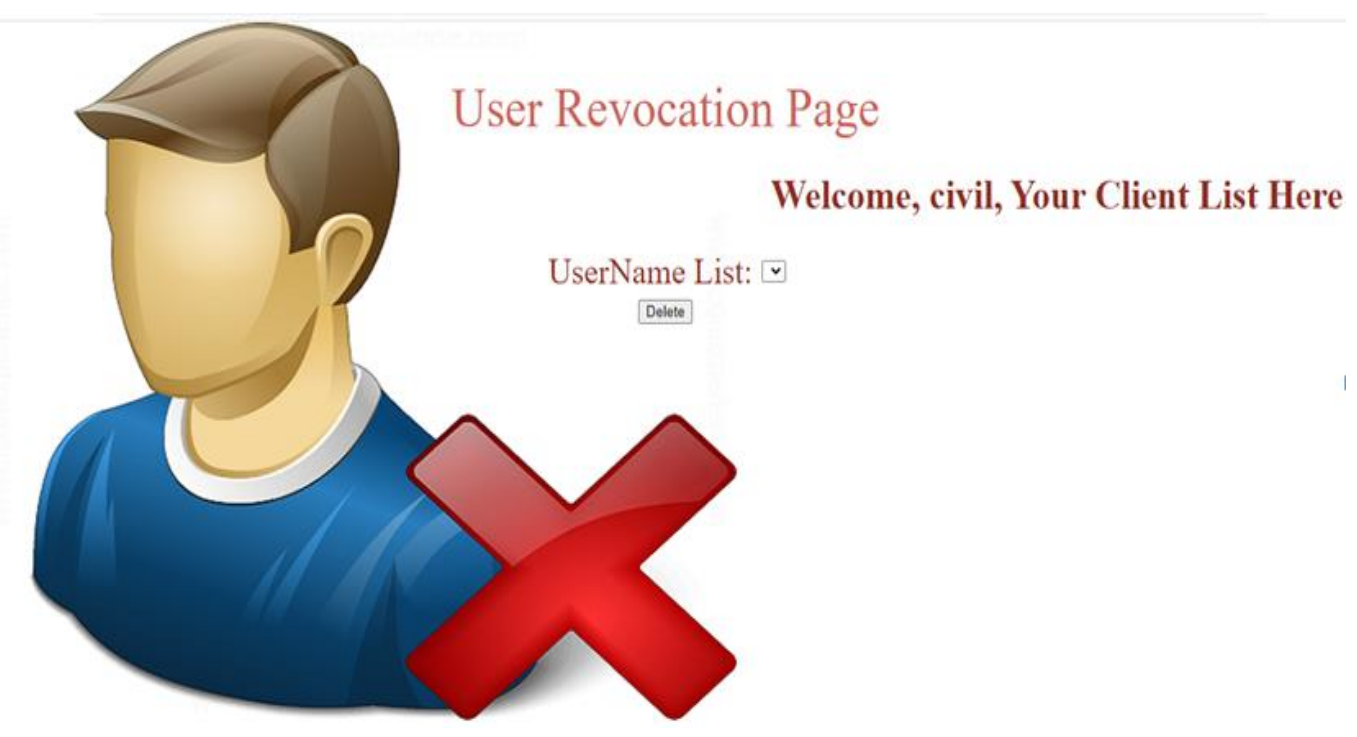

Figure: 9 User Revocation

\section{PERFORMANCE ANALYSIS}

The existing and proposed system are analysed. The problems can be easily rectified with this concept. Nearly $70 \%$ of the performance has been increased.

\section{Conclusion}

The design a secure data sharing scheme, job for dynamic groups in an un trusted cloud. In job, a user is able to share data with others in the group without revealing identity privacy to the cloud. Additionally, job portal supports efficient user revocation and new user joining. More specially, efficient user revocation can be achieved through a public revocation list without updating the 
private keys of the remaining users, and new users can directly decrypt files stored in the cloud before their participation. Moreover, the storage overhead and the encryption computation cost are constant. Extensive analyses show that our proposed scheme satisfies the desired security requirements and guarantees efficiency as well.

\section{FUTURE ENHANCEMENT}

This paper, I propose a secure data sharing scheme, named job portal, for dynamic groups in the cloud. By leveraging group signature and dynamic broadcast encryption techniques, any cloud user can anonymously share data with others. Meanwhile, the storage overhead and encryption computation cost of our scheme are independent with the number of revoked users. In addition, we analyse the security of our sc. We would like to add online preliminary exam and interview.

\section{REFERENCES}

[1]. Marjan Mansourvar and NoZrizan Binti Mohd Yasin, "Development of a Job Web Portal to Improve Education Quality", 1, February 2014.

[2] Pooja T. Killewale, Prof A.R. Mune, "A Review on: Job Portal - A Web Application for clients", May 2017

[3] Gulam Mujtaba Hussain Aqueel, Azbar Sadiqa Jabeen, “A Online Job portal management system”, February 2017.

[4] PAVAN P APARANJI, JAI PRAKASH TRIPATHI, "REVIEW OF JOB PORTAL IN RECUIREMENT", January 2018.

[5] G. Adomavicius, and A. Tuzhilin, "Toward the Next Generation of Recommender Systems: A Survey of the State-of-the-Art and Possible Extensions," IEEE Trans. Knowl. Data Eng. , pp. 734- 749,2005.

[6.] G. Linden, B. Smith, and J. York, "Amazon.com Recommendations: Item-to-Item Collaborative Filtering," Published by the IEEE Computer Society, IEEE Internet Comput., vol. 7, no.1, pp. 76-80, 2003.

[7] S. Lanning, and J. Bennett, "The Netflix Prize," in ACM digital library, San Jose, California, USA, August 12, 2007.

[8] J. Malinowski, T. Keim, O. Wendt, and T. Weitzel, "Matching People and Jobs. A Bilateral Recommendation Approach," Proceedings of the 39th Hawaii International Conference on System Sciences, Kauia, HI, USA IEEE, January 23rd , 2006.

[9] I. Paparrizos, B. Cambazoglu, and A. Gionis "Machine Learned Job Recommendation," RecSys '11 Proceedings of the fifth ACM conference on Recommender systems, Chicago, Illinois, USA, pp. 325328, October 23-27, 2011.

[10] B. R, "Hybrid Web Recommender Systems," The Adaptive Web: Methods and Strategies of Web Personalization, Verlag Berlin Heidelberg, Springer, pp. 377-408, 2007.

[11] F. Cacheda, V. Carneiro, D. Fernández, and V. Formoso "Comparison of collaborative filtering algorithms: Limitations of current techniques and proposals for scalable, high-performance recommender systems," ACM Trans., vol. 5, no. 1, New York, NY, USA February 2011. 


\section{AuTHORS}

Mr. K.Venkatesh Prabu doing final year MCA in Francis Xavier Engineering College

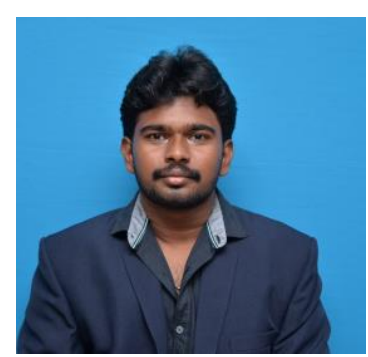

Mrs. Sujitha working as Assistant Professor in the Department of Computer Applications, Francis Xavier Engineering College. Her area of interest is Wireless Sensor networks

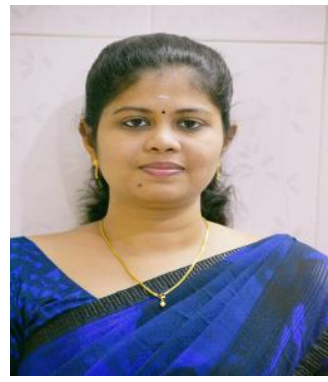

Muppidathi@Priya doing first year MCA in Francis Xavier Engineering College

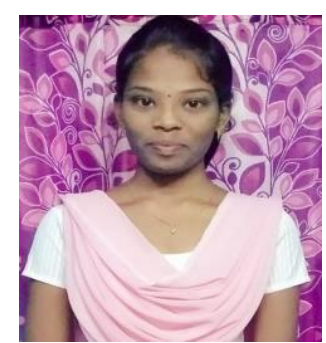

